\title{
A novel REBOA system: prototype and proof of concept
}

\author{
Maj Shane A. Smith, MD, MSc \\ LCol Vivian C. McAlister, MB
}

This study was presented in part at the Excelsior Surgical Society and ACS Clinical Congress, San Diego, Calif., Oct. 22, 2017.

Accepted Oct. 10, 2018

\section{Correspondence to:}

S. Smith

University Hospital, C8-114

339 Windermere Rd

London ON N6A 5A5

shane.smith@Ihsc.on.ca

DOI: 10.1503.cjs.015718
Background: Lower torso hemorrhage is a significant cause of death from injuries in combat. Resuscitative endovascular balloon occlusion of the aorta (REBOA) has been used to rescue patients successfully in the hospital setting, but its prehospital use is controversial. We designed a device that would be easy to use, safer in injured vessels, migration-resistant and amenable to a prehospital environment.

Methods: We designed a novel, balloon-led device using common commercial materials. Thin latex rubber was reassembled in cylindrical conformation aligned to the shape of the aorta and invaginated into vinyl tubing. The catheter is placed into the femoral vessel, followed by expression of the balloon with $\mathrm{CO}_{2}$ inflation in a proximal direction to navigate and treat damaged pelvic vasculature, occluding the distal aorta. The system was tested on model aortas (both intact and injured cadaveric porcine aorta) with inline fluid flow and pressure monitoring to determine the maximum pressure the balloons could occlude. The device was also tested on a perfused human cadaveric model.

Results: Flow was occluded with the balloon up to an average of $561.1 \pm 124.3 \mathrm{~mm} \mathrm{Hg}$. It always ruptured before causing damage to the porcine aorta and was able to occlude injured iliac vessels and proceed to occlude the distal aorta. The device was effective in occluding the distal aorta of a perfused human cadaver.

Conclusion: This novel, high-volume, low-pressure device can occlude the distal aorta in a simulated human aorta model, cadaveric porcine model and perfused human cadaver. It can occlude fluid flow to supraphysiologic pressures. It is easy to use, migration-resistant, able to navigate and treat injured pelvic vessels, and amenable to prehospital care.

Contexte : L'hémorragie au bas du corps est une importante cause de décès suite aux blessures subies au combat. L'occlusion aortique endovasculaire par ballonnet a été utilisée avec succès comme mesure de réanimation chez des patients hospitalisés, mais son utilisation dans un contexte préhospitalier est controversée. Nous avons conçu un instrument qui serait facile à utiliser, plus sécuritaire en présence de vaisseaux lésés, peu sujet à migrer et adapté au contexte préhospitalier.

Méthodes : Nous avons conçu un nouvel instrument guidé par ballonnet et fabriqué à l'aide de matériaux d'usage courant. Du caoutchouc de latex mince a été façonné en cylindre pour épouser la forme de l'aorte et introduit dans un tube de vinyle. Le cathéter est ensuite inséré dans la veine fémorale, après quoi il est gonflé avec du $\mathrm{CO}_{2}$ en direction proximale pour atteindre et traiter le réseau vasculaire pelvien et créer une occlusion aortique distale. Le système a été mis à l'essai sur des aortes modèles (aortes de cadavres de porcs intactes et lésées), avec surveillance interne du débit et de la pression pour déterminer la pression maximale contre laquelle le ballonnet est capable de créer l'occlusion. L'instrument a aussi été testé sur un modèle de cadavre humain perfusé.

Résultats : Le ballonnet a permis l'occlusion à une pression moyenne pouvant atteindre $561,1 \pm 124,3 \mathrm{~mm} \mathrm{Hg}$. Il s'est toujours rompu avant de pouvoir endommager l'aorte porcine et a permis l'occlusion des vaisseaux iliaques lésés et ensuite de l'aorte distale. L'instrument a permis l'occlusion efficace de l'aorte distale d'un cadavre humain perfusé.

Conclusion : Ce nouvel instrument à fort volume et faible pression permet de créer l'occlusion de l'aorte distale dans un modèle simulé d'aorte humaine, dans un modèle de cadavre porcin et sur un cadavre humain perfusé. Il est facile à utiliser, peu susceptible de migrer; il se déploie et traite facilement les vaisseaux pelviens lésés et convient au contexte préhospitalier. 
oncompressible torso hemorrhage is a significant cause of death from injuries in combat. ${ }^{1}$ Resuscitative endovascular balloon occlusion of the aorta (REBOA) has been used successfully in hospital settings to rescue patients. ${ }^{2}$ There is potential for a prehospital application of a REBOA device to allow severely injured combat casualties to survive to surgical care. However, REBOA use is associated with complications. We sought to design a prototype for proof of concept of a device that would be simple to use, mitigate some of the risks of REBOA and lead to the development of a device suitable for prehospital combat application.

The types of injuries suffered by combat casualties have changed. In the recent war in Afghanistan, more soldiers were injured by improvised explosive devices (IEDs) than any other weapon. ${ }^{3,4}$ These weapons cause multiple amputations and severe pelvic trauma. ${ }^{5,6} \mathrm{With}$ the wide use of personal protective equipment (PPE) and the evolution of tactical combat casualty care (TCCC), soldiers are now surviving combat wounds that once would have been lethal. ${ }^{7}$ However, IEDs, with their associated destructive pelvic injuries, can cause noncompressible hemorrhage that can kill victims ${ }^{5,6}$ This has prompted the suggestion that IED victims receive rapid application of pelvic binders and early evacuation to surgical care. ${ }^{5}$ It has also encouraged research and interest into novel ways of treating noncompressible torso hemorrhage.

REBOA has been used to treat this type of noncompressible hemorrhage. A balloon is inserted into the femoral artery and inflated in either the intrathoracic or infrarenal aorta to occlude blood flow and preserve coronary and cerebral perfusion while a patient is hurried to surgery. ${ }^{2}$ Although this technique was first described during the Korean War, it has gained popularity in the trauma and combat communities only in the past decade. ${ }^{2}$ There are now military and civilian registries tracking REBOA use and monitoring outcomes. ${ }^{8}$ The technique has been used successfully in Afghanistan and Iraq and has even been used in prehospital environments. ${ }^{9}$ A retrospective gap analysis indicated that as many as $18 \%$ of combat casualties could benefit from REBOA. ${ }^{10}$ Morrison and colleagues ${ }^{10}$ analyzed the UK trauma registry and found that over a 10-year period, 174 deaths met indications for REBOA but that $83 \%$ of these patients died before reaching hospital, with a mean time of death of 75 minutes. Although REBOA has been used successfully in combat hospitals, in order for it to have a major impact on combat mortality it needs to be used in a presurgical environment.

There are case reports of successful prehospital use in both military and civilian environments; however, these cases were performed by surgeons and specially trained emergency physicians. Although success may be achievable in civilian air ambulance ${ }^{11}$ and special forces environments, ${ }^{9}$ it is not feasible for wide combat application. In order for REBOA to help save regular soldiers' lives, a general duty medical officer or physicians' assistant must be able to deploy the device in a presurgical environment. Consideration of prehospital use of combat REBOA has recently been published. ${ }^{12,13}$

REBOA is associated with potential complications. There can be complications of arterial access, balloon positioning, balloon migration, de novo or exacerbation of arterial injuries, and ischemic burden. ${ }^{14} \mathrm{We}$ believe that our prototype design concept can be developed into a technology that will be easier and safer to use, and suitable for a presurgical environment.

\section{Methods}

\section{Device construction}

Rather than using a Seldinger technique, guiding the apparatus over a wire, in our technique a latex balloon expands up the vessel as it inflates, making the device self-guided. The $16 \mathrm{~mm} \times 22 \mathrm{~cm}$ balloon inflates up the vessel (Fig. 1 and Fig. 2). The balloon is inflated from a pressurized 16-g $\mathrm{CO}_{2}$ canister. This was attached with a variable valve allowing for control of inflation and a pressure gauge to monitor internal pressure of the balloon. A ball valve was used as a pressure release to allow for deflation of the balloon and retraction of the device. As the balloon expands, it carries a wire that is attached inside the balloon, which allows for a measurement of length of deployment as well as the application of gentle pressure to facilitate deployment. The braided wire $(1.1 \mathrm{~mm}$ in diameter) enters the device through a rubber seal of near identical diameter. When the balloon device is deployed, a plastic bead is pulled into the rubber seal. The more the balloon inflates, the greater the force of the bead pressing into the seal, preventing air leak. The balloon is $22 \mathrm{~cm}$ in length and $1.6 \mathrm{~cm}$ in diameter, and is made of $0.05 \mathrm{~mm}$ latex. It begins invaginated in the

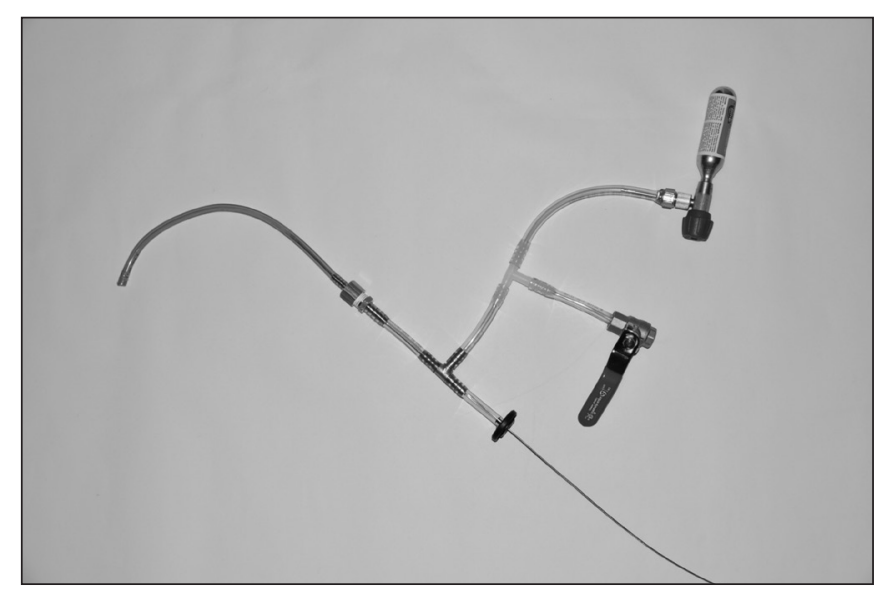

Fig. 1. Novel aortic occlusion device. The balloon is invaginated in the catheter and is deployed by $\mathrm{CO}_{2}$. The wire attached to the balloon measures depth and distance of deployment and allows for removal. 
device and then inflates and deploys longitudinally with $\mathrm{CO}_{2}$ inflation. Once maximum length is achieved, the balloon further distends laterally. The deployment catheter has an external diameter of $6.35 \mathrm{~mm}$ and an internal diameter of $2.76 \mathrm{~mm}$.

\section{Pressure testing}

A testing model was created in order to determine against what pressure the device could obtain and maintain occlusion. It consisted of a vinyl model aorta $2 \mathrm{~cm}$ in diameter with vinyl iliac limbs $2 \mathrm{~cm}$ in diameter; water was pumped through the model at variable pressures. A pressure gauge was placed in continuity with the water flow to measure how high the water pressure could be raised while maintaining balloon occlusion before rupture. A variable speed pump was used to increase the water pressure until rupture was obtained and the rupture pressure recorded. The device was then deployed in a human-sized vinyl model with a $2 \mathrm{~cm}$ aorta and $1 \mathrm{~cm}$ iliac arteries (Fig. 3).

\section{Occlusion of cadaveric porcine aorta}

Porcine aortas were obtained from a local abattoir. The experiments were conducted on the day of slaughter. The cadaveric porcine aorta was placed into the testing apparatus, replacing the artificial tubing. Small arterial branching vessels were suture-ligated. The prototype device was then used to cause flow occlusion (Fig. 4). Normal saline was infused through the testing apparatus during cadaveric porcine experiments. The first aorta had a $20 \mathrm{~mm}$ internal diameter with $15 \mathrm{~mm}$ iliac arteries, the second had an $18 \mathrm{~mm}$ diameter with $13 \mathrm{~mm}$ iliac arteries, and the third had an $18 \mathrm{~mm}$ diameter with $14 \mathrm{~mm}$ iliac arteries.

\section{Modelling damaged iliac vessels}

In order to model the balloon progression and occlusion of flow that would occur in a damaged iliac vessel, a $1 \mathrm{~cm}$ diameter defect was cut in the iliac vessel of the porcine model. The device was then used to inflate up the damaged limb. This procedure was done on 3 different porcine aortas. Three different balloons were used on each model, for a total of 9 balloons tested (Fig. 5).

\section{Perfused cadaver testing}

Cadavers were provided through the bequeathal program, Department of Anatomy and Cell Biology, Western University, London, Ontario, Canada, in accordance with the Anatomy Act of Ontario. These cadavers were never treated with formalin and were preserved by freezing until they were thawed for the experiments. A human cadaver had a catheter inserted in its subclavian artery and was perfused with a water and red dye solution. The femoral arteries were dissected bilaterally. The device was deployed in the right common femoral artery, and flow through a left femoral arteriotomy was observed for occlusion. The cadavers were perfused to a pressure of $120 \mathrm{~mm} \mathrm{Hg}$ (Fig. 6).

\section{Results}

\section{Occlusion pressure testing}

The invaginated balloon of the device expanded out of the tip of the catheter until it reached its full length of $22 \mathrm{~cm}$, and then further stretched to the diameter of the aorta, up to a maximum of $5.5 \mathrm{~cm}$

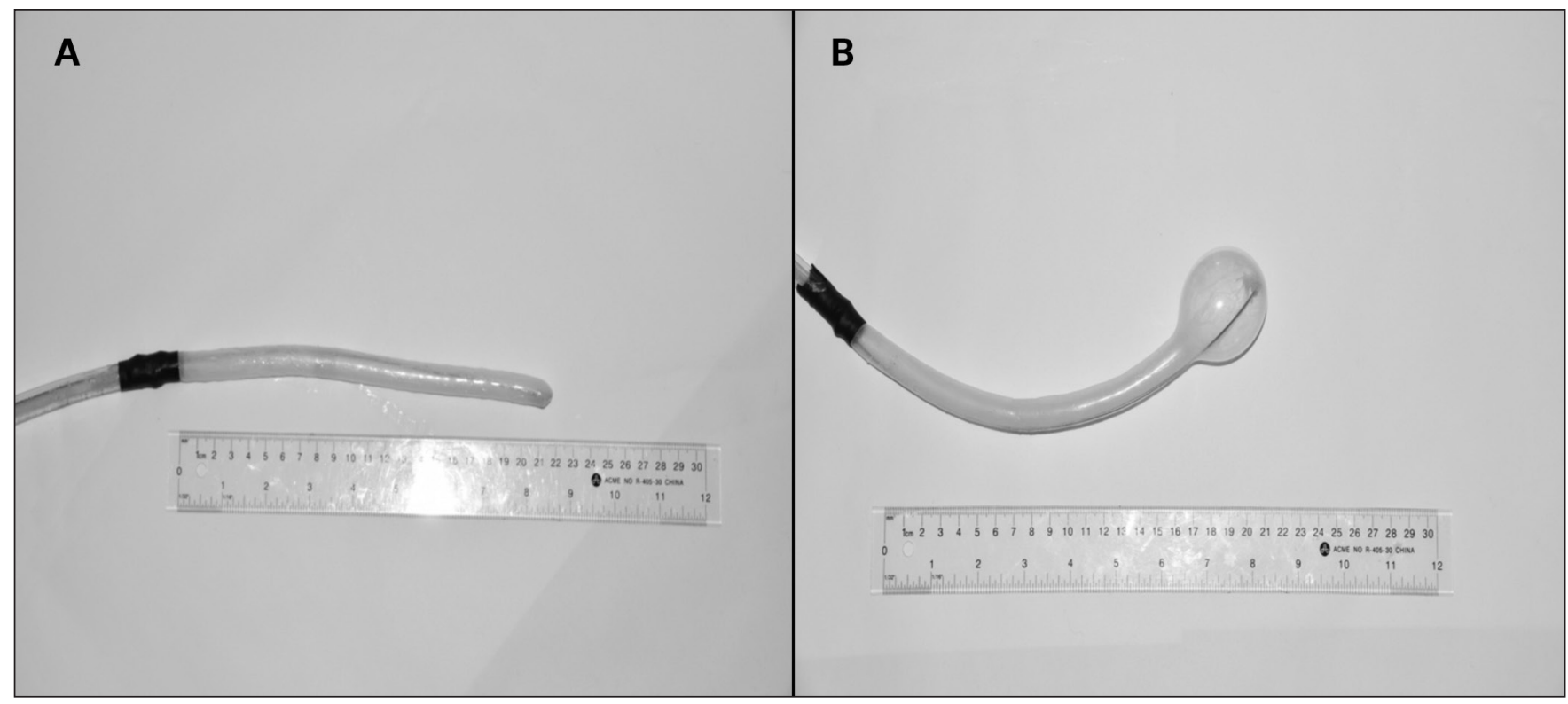

Fig. 2. The invaginated balloon (A) deploys up to $22 \mathrm{~cm}$ and then (B) can dilate to $5.5 \mathrm{~cm}$ to cause aortic occlusion. 
(Fig. 1). The device was deployed into the occlusion pressure testing apparatus. Once occlusion had been obtained, the upstream water pressure was gradually increased until the balloon ruptured. The mean rupture pressure was $561 \pm 124 \mathrm{~mm} \mathrm{Hg}$, with a minimum rupture pressure of $362 \mathrm{~mm} \mathrm{Hg}$, which is well above any physiological human blood pressure (Fig. 7). The internal pressures of the balloon were also measured and were equal to upstream pressures at the time of rupture. The device was then tested on aortic models of human anatomical scale; it was also successful in occluding flow in this model.

\section{Porcine aortic model}

A porcine aorta was attached to the perfusion apparatus. The device was deployed up the porcine iliac arteries and aorta and occluded fluid flow. The device successfully

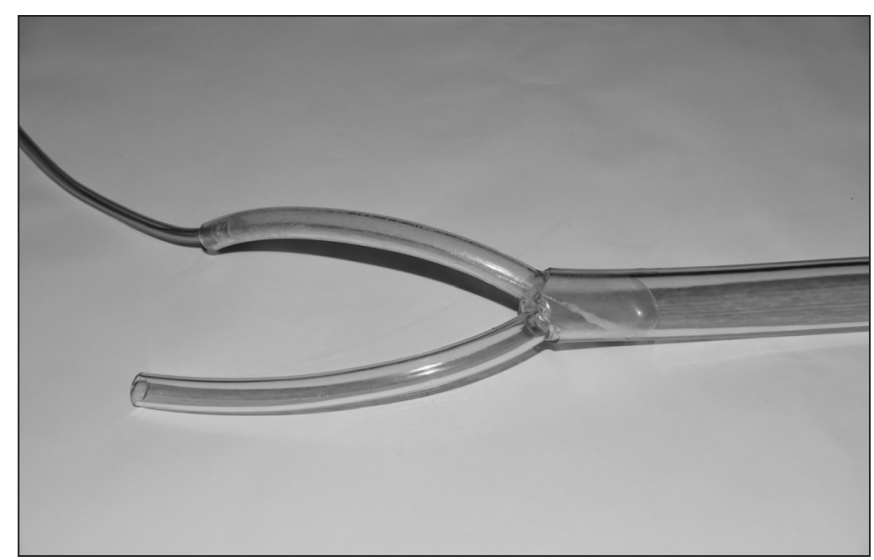

Fig. 3. Device causing occlusion of a human aorta-sized model with a $2 \mathrm{~cm}$ aorta and $1 \mathrm{~cm}$ iliac artery. occluded flow of water in a porcine aorta model with a perfusion pressure of $120 \mathrm{~mm} \mathrm{Hg}$ (Fig. 4). Nine balloons that were tested were able to provide effective occlusion. When a $1 \mathrm{~cm}$ defect was cut in the iliac vessel to simulate a traumatically damaged vessel, the balloon was able to fill the defect and continue on its proximal course to cause occlusion (Fig. 5).

\section{Human perfused cadaver testing}

The device was deployed in the right femoral artery of a perfused cadaver model. When it was deployed, flow through the arteriotomy in the left femoral artery stopped, showing proximal occlusion. The cadaver was perfused to a pressure of $120 \mathrm{~mm} \mathrm{Hg}$ (Fig. 6).

\section{Discussion}

In order for prehospital use of a REBOA device to be feasible, it needs to be easy to use and as safe as possible. We have designed a prototype as proof of concept in an attempt to mitigate some of the complications associated with REBOA.

The expanding cylindrical balloon self-guides to placement. With this novel device, the operator does not need to be a skilled endovascular surgeon; instead, the balloon leads the way. If the iliac vessel is injured, the balloon may fill the defect and continue to expand proximally. If proximal navigation is impossible, the balloon will inflate at the site of injury and may cause tamponade. This technique is similar to the previously established technique of inflating a Foley catheter into a junctional injury for tamponade. If the device does not advance because of iliac injury, a second device can be

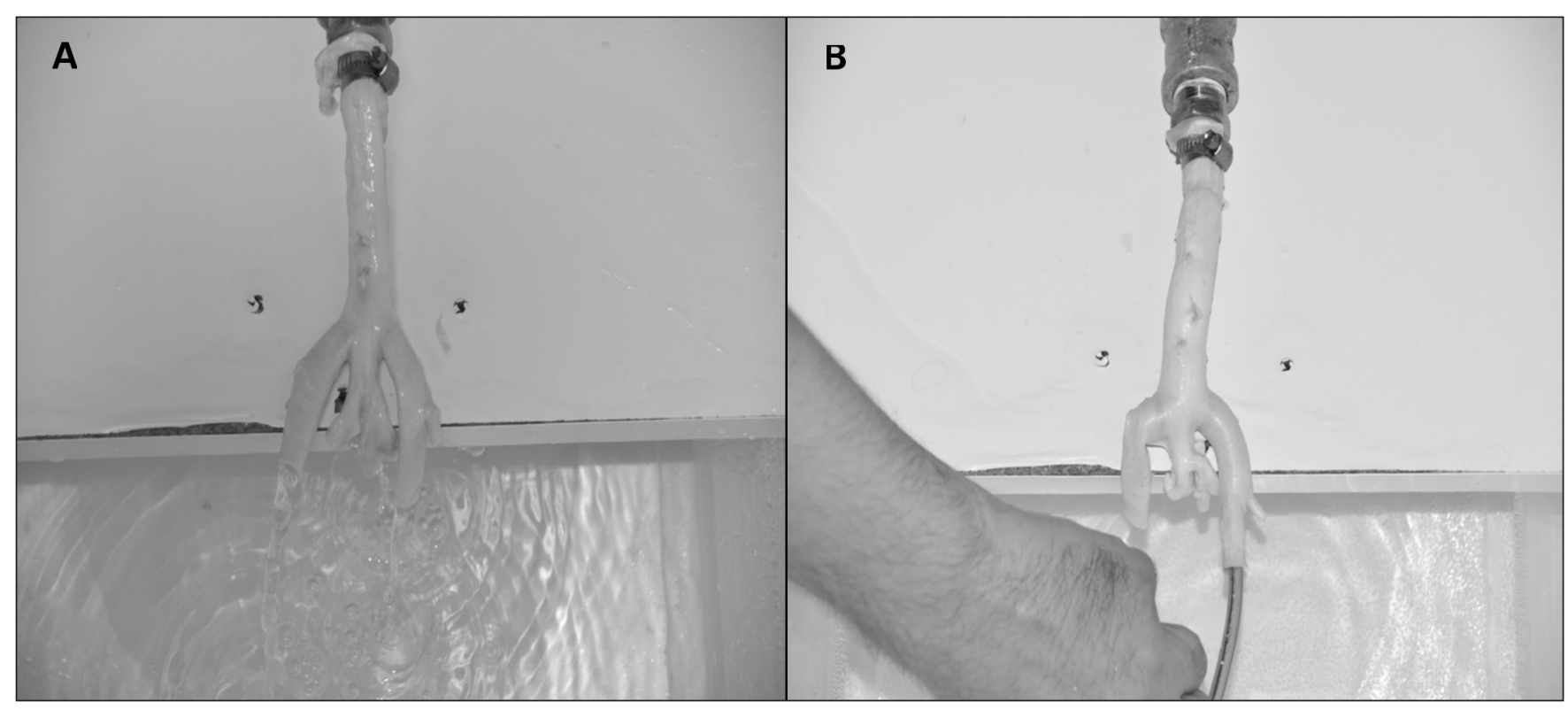

Fig. 4. (A) Porcine aorta is perfused at $120 \mathrm{~mm} \mathrm{HG}$. (B) Occlusion is obtained using the device. 
inserted into the contralateral side. If, again, it cannot be advanced, both can be left in place, causing bilateral iliac tamponade and helping hemorrhage control. This novel device is superior to traditional REBOA, where if the catheter cannot be safely advanced to its final placement, the technique must be aborted.

One of the dangers of standard REBOA application is that the catheter may descend down the contralateral iliac artery or be inserted too far into the subclavian artery or even the heart. The advantage of our prototype is that if the balloon goes down the contralateral iliac vessel, bilateral iliac occlusion can be obtained safely as the balloon inflates up one limb and down the other. The length of the balloon defines its maximum travel distance, making subclavian or intracardiac deployment impossible. If a traditional REBOA balloon is inflated in the iliac vessel accidentally, it is possible to exacerbate an iliac injury or cause vessel rupture. With our device, the soft, low-tension balloon inflates the entire length of the vessel and does not carry the risk of inadvertently inflating a less compliant balloon. Because there is such little anatomic variability in the distance from the common femoral artery to the iliac bifurcation, a fixed-length balloon will likely be able to provide consistent and safe infrarenal occlusion. This feature, combined with potential for increased safety of a low-tension balloon, would alleviate the need for radiographic conformation of placement. Finally, one problem associated with REBOA catheters can be migration after inflation. The inflated balloon is pushed with each heartbeat and has a small

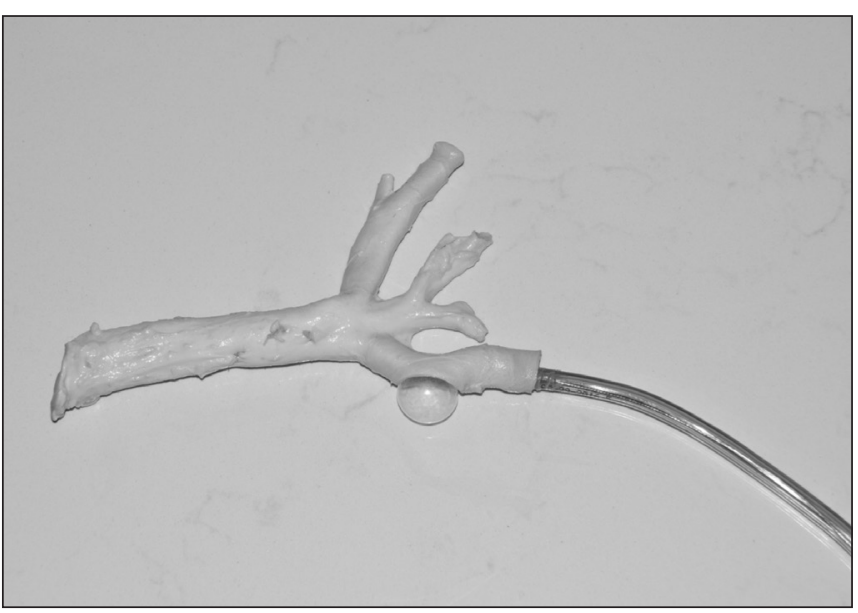

Fig. 5. A 1-cm defect in a porcine iliac is filled by the balloon as it continues its course.

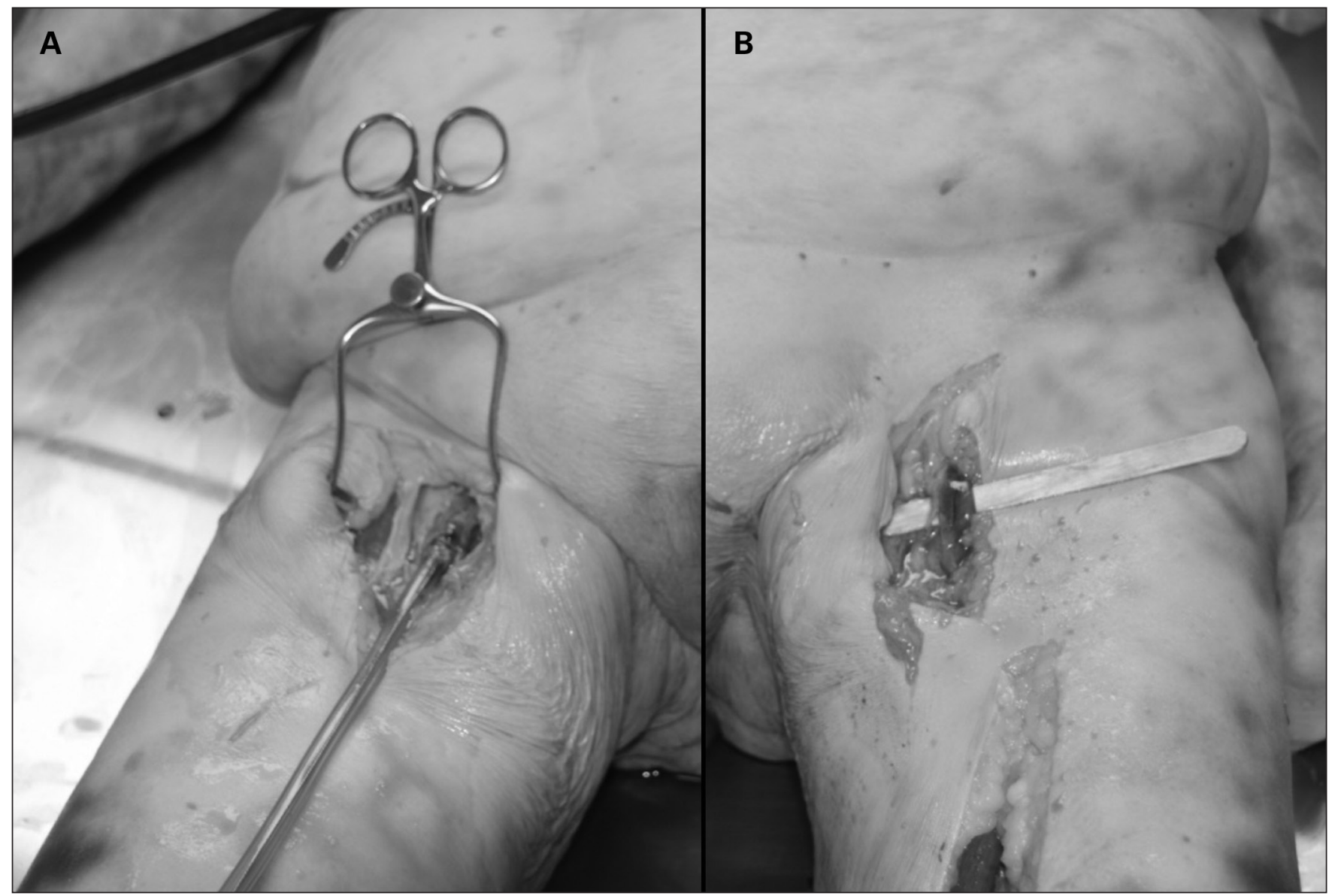

Fig. 6. Occlusion of flow in a perfused cadaver model. (A) The device was deployed in the right common femoral artery, and (B) flow through a left femoral arteriotomy was observed for occlusion. 


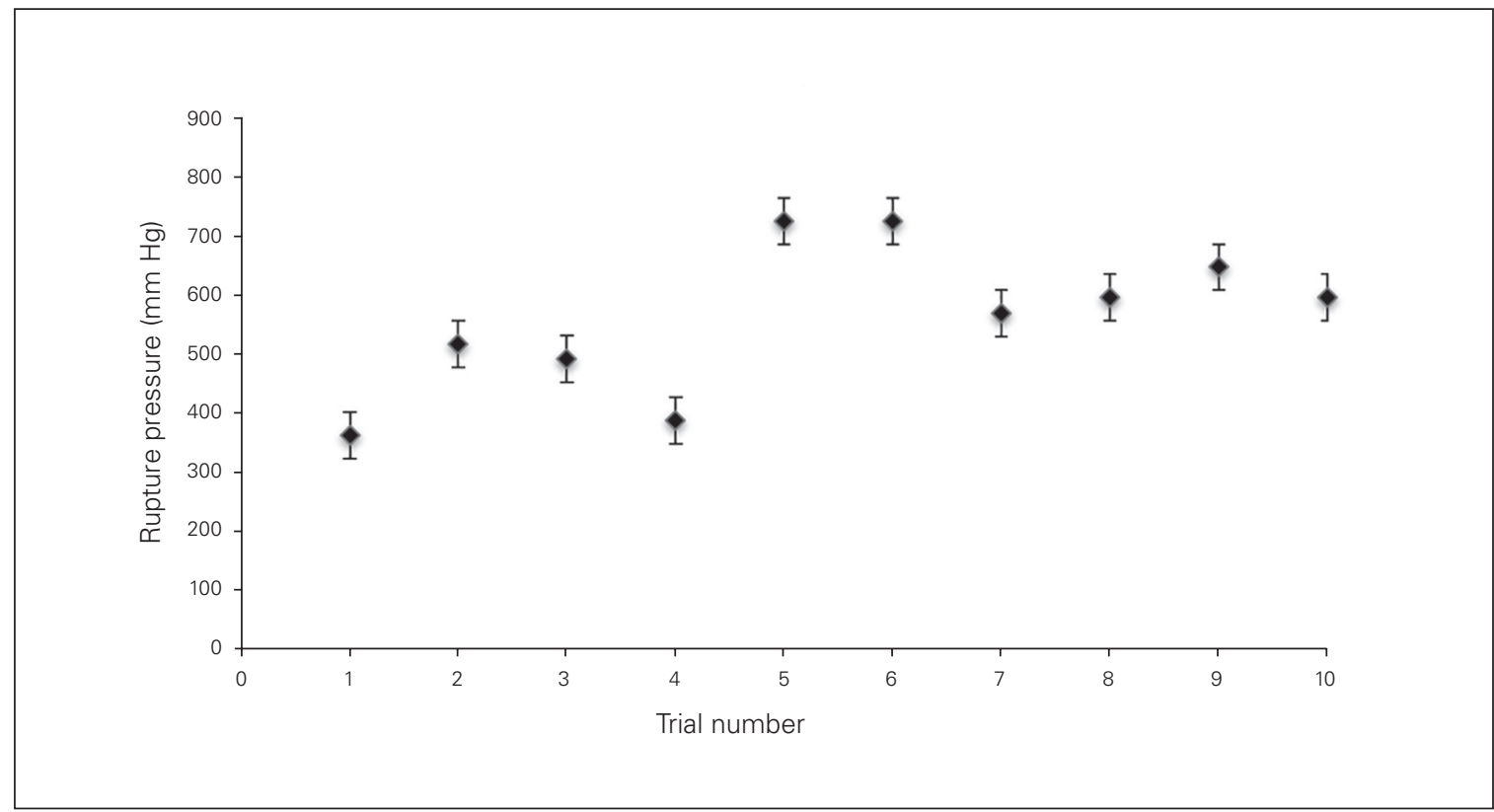

Fig. 7. Rupture pressures for 10 balloons. The error bars represent standard error measurement.

area of contact with the vessel wall. Our device has contact through the entirety of the vessel, from the point of insertion to the point of maximum deployment, which makes migration of a deployed balloon near impossible. These features make this novel device more suitable than traditional REBOA for a presurgical application.

Traditional REBOA balloons are inflated with saline, not $\mathrm{CO}_{2}$. Although a variant of this novel device can be produced with hydroinflation, $\mathrm{CO}_{2}$ inflation has some advantages. The $\mathrm{CO}_{2}$ cartridges are small, light and easily managed. The main advantage of water inflation is that it is essentially noncompressible. Once the balloon is inflated and occlusion is achieved, the balloon will not be compressed as blood pressure is restored. With the $\mathrm{CO}_{2}$-inflated balloon, as blood pressure increases the balloon will be compressed and it is possible that more $\mathrm{CO}_{2}$ will need to be put into the balloon. However, this compressibility is advantageous when inflating the balloon in a damaged iliac artery. Rather than damaging the vessel with a noncompressible expanding water balloon, a gentler and softer compressible balloon fills the space of the defect while minimizing further destruction of the vessel. The compressibility of $\mathrm{CO}_{2}$ makes it perfect for this application. As has been shown in our experiments, occlusion of flow to supraphysiological levels can still be achieved. In addition, similar to the reason for its use in laparoscopic surgery, $\mathrm{CO}_{2}$ is a good choice in the event of balloon rupture because the gas is rapidly absorbed and expelled through the lungs. Any gas embolism formed would be in the distal circulation and unlikely to cause cardiac or brain gas embolism. With its small containers, ease of use, compressibility and physiologic absorption, $\mathrm{CO}_{2}$ is an ideal choice for our device.

The low-tension, pliable balloon may also be bettersuited to damaged vessels. It does not require radiographic confirmation of placement, and its large surface area makes it resistant to migration. With further development and physiological testing, our device may be able to be implemented in a prehospital environment to help patients survive to surgical care.

Our future work is focused on developing a $5-\mathrm{Fr}$ balloon as well as a longer balloon system that could provide thoracic aortic occlusion.

\section{Conclusion}

Current REBOA devices have been shown to have military utility and have already been used in deployed operations. We believe our prototype has shown proof of concept of an approach that may be safer in blast-injured vessels, easier to use, and have prehospital combat casualty application.

Affiliations: From the Royal Canadian Medical Service and the Department of Surgery, Western University, London, Ont.

Competing interests: None declared.

Contributors: S. Smith built the device and testing apparatuses and conducted the experiments, which both authors designed. Both authors wrote and reviewed the article, approved the final version for publication, had full access to all of the study data and agree to be responsible for the integrity of the data and the accuracy of the data analysis.

Data sharing: No additional data are available.

Disclaimer: The views expressed in this paper are those of the authors and do not constitute the views or policies of the Canadian Armed Forces. 


\section{References}

1. Morrison JJ, Stannard A, Rasmussen TE, et al. Injury pattern and mortality of noncompressible torso hemorrhage in UK combat casualties. 7 Trauma Acute Care Surg 2013;75:S263-8.

2. Belenkiy SM, Batchinsky AI, Rasmussen TE, et al. Resuscitative endovascular balloon occlusion of the aorta for hemorrhage control: Past, present, and future. 7 Trauma Acute Care Surg 2015;79:S236-42.

3. Beckett A, Pelletier P, Mamczak C, et al. Multidisciplinary trauma team care in Kandahar, Afghanistan: current injury patterns and care practices. Injury 2012;43:2072-7.

4. Jacobs N, Taylor DM, Parker PJ. Changes in surgical workload at the JF Med Gp Role 3 Hospital, Camp Bastion, Afghanistan, November 2008-November 2010. Injury 2012;43:1037-40.

5. Smith S, Devine M, Taddeo J, et al. Injury profile suffered by targets of antipersonnel improvised explosive devices: a prospective cohort study. BM7 Open. In press.

6. Cannon JW, Hofmann LJ, Glasgow SC, et al. Dismounted complex blast injuries: a comprehensive review of the modern combat experience. 7 Am Coll Surg 2016;223:652-664.e658.

7. Savage E, Forestier C, Withers N, et al. Tactical combat casualty care in the Canadian Forces: lessons learned from the Afghan war. Can 7 Surg 2011;54:S118-23.
8. DuBose JJ, Scalea TA, Brenner M, et al. The AAST Prospective Aortic Occlusion for Resuscitation in Trauma and Acute Care Surgery (AORTA) Registry: data on contemporary utilization and outcomes of aortic occlusion and resuscitative balloon occlusion of the aorta (REBOA). 7 Trauma Acute Care Surg 2016;81:409-19.

9. Manley JD, Mitchell BJ, DuBose JJ, et al. A modern case series of resuscitative endovascular balloon occlusion of the aorta (REBOA) in an outof-hospital, combat casualty care setting. 7 Spec Oper Med 2017;17:1-8.

10. Morrison JJ, Ross JD, Rasmussen TE, et al. Resuscitative endovascular balloon occlusion of the aorta: a gap analysis of severely injured UK combat casualties. Shock 2014;41:388-93.

11. Mundasad S. Balloon surgery stops fatal bleeding at roadside. $B B C$ News 2014 June 17. Available: www.bbc.com/news/health-27868418 (accessed 2018 Oct. 10).

12. Smith SA, Hilsden R, Beckett A, et al. The future of resuscitative endovascular balloon occlusion in combat operations. 7 R Army Med Corps 2017; 10.1136/jramc-2017-000788.

13. Fisher $\mathrm{AD}$, Teeter WA, Cordova CB, et al. The Role I resuscitation team and resuscitative endovascular balloon occlusion of the aorta. $\mathcal{F}$ Spec Oper Med 2017;17:65-73.

14. Davidson AJ, Russo RM, Reva VA, et al. The pitfalls of REBOA: risk factors and mitigation strategies. 7 Trauma Acute Care Surg 2017; 10.1097/TA.0000000000001711. 